\title{
Prognostic significance of SOX2 and GPC3 in Ameloblastoma and its malignant counterpart (Ameloblastic Carcinoma)
}

\author{
Shaza I.A. Hasan* Sherief Y.M. El Nagdy, Mona M.A. Ibrahim \\ Oral pathology department, Dentistry Faculty, Mansoura University, Mansoura, Egypt
}

Received: May 30, 2021

DOI: $10.5430 /$ jst.v $11 \mathrm{n} 1 \mathrm{p} 1$
Accepted: September 13, 2021

Online Published: September 26, 2021

\begin{abstract}
Background: Ameloblastoma is a common benign aggressive odontogenic tumor with a tendency for high recurrence rate. Ameloblastic Carcinoma is the malignant counterpart of Ameloblastoma. However, they are usually difficult to be distinguished from one another. Therefore, using Immunohistochemical markers might be beneficial for diagnosing them accurately.

Objective: Evaluation of SOX2 and GPC3 expressions as well as evaluating their roles in the tumorigenesis and the biological behavior of Ameloblastoma and Ameloblastic Carcinoma.

Methods: Tissue samples are composed of 34 archived histopathologically confirmed cases of (19 Conventional Ameloblastomas, and 15 Ameloblatic Carcinomas). Sections were subjected to Immunohistochemical staining according to a standard protocol by applying antibodies to SOX2, and GPC3.

Results: SOX2 and GPC3 expressions in recurrent Ameloblastoma were significantly higher than non- recurrent cases. Ameloblastic Carcinoma showed the highest immune-reactivity to SOX2 and GPC3 compared to the Conventional Ameloblastoma. Desmoplastic Ameloblastoma showed the highest scores of SOX2 and GPC3 compared to the other subtypes.

Conclusions: SOX2 and GPC3 can be used as a panel for diagnosing the aggressive and the malignant odontogenic tumors accurately. Desmoplastic Ameloblastoma behaves more aggressively than other Conventional Ameloblastoma subtypes.
\end{abstract}

Key Words: Ameloblastoma, Ameloblastic Carcinoma, Immunohistochemistry, SOX2, GPC3

\section{INTRODUCTION}

Odontogenic tumors (OTs) are a group of various lesions that range from hamartomatous to malignant. These tumors have various clinical behaviors and histopathological types. ${ }^{[1]}$ Ameloblastoma (AB) is the commonest benign OT. It is a local aggressive tumor originating from the epithelium with a high recurrence rate and a liability for malignancy changes as well as metastasis. ${ }^{[2]}$ Ameloblastic Carcinoma (AC) is rare and is more aggressive malignant OT than AB. It has malignant histopathological characters such as: cytological atypia, necrosis and clear cells along with the benign histological features of $\mathrm{AB}$ even in the absence of metastasis. ${ }^{[3]}$ To date, the exact incidence rate of AC is still unknown and a relatively few cases have been reported. Moreover, many cases have been misdiagnosed as $\mathrm{AB}{ }^{\left[{ }^{4]}\right.}$ Therfore, specific immunohistochemical (IHC) markers are needed.

The progression of these tumors involves a series of genetic and molecular alterations that are still not clear. This may be Egypt.

*Correspondence: Shaza I. A. Hasan; Email: shazaismail44@gmail.com; Address: 28 Al Aresh Street, Toril EL Gededa, Mansoura, Dakahlia, 
attributed to the presence of cancer stem cells (CSCs). ${ }^{[5,6]}$ CSCs are involved in the initiation of metastasis and are responsible for therapeutic resistance. As a consequence, they promote tumor progression and recurrence. ${ }^{[7]}$ SOX2 is a transcription factor which is considered as a subpopulation of stemness-related genes. ${ }^{[8]}$

SOX2 protein has a role in pluripotency maintenance of embryonic stem cells (ESCs). ${ }^{[9]}$ It is involved in the development of ectoderm in early ESCs stages, ${ }^{[10]}$ from which the odontogenic epithelium originates. ${ }^{[1]}$ SOX2 has a role in tumorigenesis of different types of human cancers ${ }^{[12,13]}$ and OTs. ${ }^{[14]}$

GPC3 is a member of the glypican family (GPC1 to GPC6) that gets attached to the cell's surface. It contains 14 highly conserved "cysteine residues". ${ }^{[15]}$ It has a role in cell growth and differentiation. ${ }^{[16]}$ GPC3 is a potential liver cancer therapeutic target as it is highly expressed in Hepatocellular Carcinoma (HCC) ${ }^{[17]}$ Furthermore, it is found in different types of human Cancers. ${ }^{[18]}$ However, the significance of GPC3 as a diagnostic and prognostic marker for human tumors other than HCC is still unclear.

\section{Material AND Methods}

\subsection{Tissue samples}

This study was retrospectively applied on 34 formalin fixed and paraffin embedded tissue blocks (19 Conventional ABs and 15 ACs). These blocks were collected between the years 2009 and 2019 from archives of oral pathology labs, Faculties of Dentistry; Mansoura University and Alexandria University. Tooth germ tissue was used as a normal tissue control. SOX2 positive tissue control was Squamous cell carcinoma (SCC). GPC3 positive tissue control was HCC. This work was approved by the local Ethics Committee in Research, faculty of Dentistry, Mansoura University, Egypt (Code Number A04260219).

\subsection{Immunohistochemical markers}

Universal Kit: Power Stain TM 1.0 Poly HRP DAB Kit for Mouse \& Rabbit. SOX2 antibody [EP103] (AN8335M; BioGenex, USA); Primary Rabbit Monoclonal antibody (ready to use). Anti-Glypican-3 [GPC3-88] (AM539-5M; BioGenex, USA); Primary Mouse Monoclonal Antibody (ready to use).

\subsection{Methods}

Available Clinical and radiographical data was retrieved from the patients' files. Four serial tissue sections were cut at $4 \mu$ thickness (one section for H\&E staining to confirm diagnosis according to the WHO Histopathological Classification of OTs ${ }^{[19]}$ and three sections were mounted on positively charged glass slides for assessment of SOX2 and GPC3 expressions according to their manufacturer's instructions).

Sections were deparaffinized in xylene and rehydrated in alcohol with descending concentrations. Antigen retrieval was performed. Slides were immersed in citrate buffer PH6 (10 minutes), heated, blocked (30 minutes) with $1.5 \%$ horse serum "Santa Cruz Biotechnology" and finally were diluted in phosphate buffered solution (PBS).

Incubation of monoclonal primary antibodies was done at room temperature (45 minutes). Two drops of the following antibodies were used: anti-(SOX2, and GPC3). Slides were washed with PBS (3 minutes) twice, treated with 4-5 drops of "Ultra Vision biotinylated goat anti-polyvalent secondary antibody" (10 minutes), and then were washed in PBS (3 minutes). Slides were treated with streptavidin-biotin enzyme reagent "DAKO, Denmark" (10 minutes) and rewashed in PBS (3 minutes).

Drops of "3.3-Diaminobenzidine tetrahydrochloride" (DAB) were applied as a chromogen for color development. Slides then, were incubated (10 minutes) and then washed with PBS (3 minutes). Sections were counterstained with Mayers hematoxyline and were fixed using xylene-based mounting medium (3 minutes). Positive immune deposits were detected as brown spots.

\subsection{Evaluation}

Evaluation was assessed according to the area of positive cells' staining. Each slide was examined under a light microscope, five selected fields of tissue sections were evaluated at $400 \times$ magnifications. SOX2 expression was considered positive when brown nuclear staining of the tumor cells was seen. Expression percentages were graded from 0 to 4 according to the following levels: $0 \%, 1 \%-25 \%, 26 \%-50 \%$, $51 \%-75 \%$ and $76 \%-100 \%$. Intensity was recorded from 0 to 3 representing: Negative, Weak, Moderate and Strong respectively. The percentage and intensity scores were then added to obtain a total score. The final score ranged from 0 to 7. Expression were categorized into 1 of 3 groups: (0) Negative $=0$ point, (1) Low $=1-3$ points, and (2) High $=4-7$ points. ${ }^{[20]}$

GPC3 expression was considered positive when brown cytoplasmic staining of the tumor cells was detected. Expression percentages were graded from 0 to 4 according to the following levels: $0 \%, 1 \%-25 \%, 26 \%-50 \%, 51 \%-75 \%$ and $76 \%-100 \%$. Intensity was recorded from 0 to 3 representing Negative, Weak, Moderate and Strong. Percentage and intensity scores were then multiplied to obtain a total score that ranged from; (0) Negative $<3$, (1) Low $=3$, and (2) High $=$ at least $4 .^{[20]}$ 


\subsection{Statistical analysis}

It was performed by SPSS program version 16, IBM Corporation. Non parametric Data were compared by Mann Whitney U test (for two groups of data) and Kruskal Wallis test (For more than two groups of data). Spearman's correlation coefficient test was used to correlate different parameters. $P$ values were considered statistically significant if they were equal or less than .05 .

\section{Results}

Mean age in patients with $\mathrm{AC}(\mathrm{M}=45.5)$ that ranged from 25 to 64 was higher than the mean age of $A B$ patients $(M=$
35. 3) that ranged from 11 to 60 . Males were more frequently observed than females. They represented $58.6 \%$ of $\mathrm{AB}$ cases and $73.3 \%$ of $\mathrm{AC}$ cases. Most of the studied groups were restricted to the posterior mandible.

Radio-graphically, most of the studied AB cases $86.2 \%$ appeared as well-defined multilocullar radiolucency, often without cortical perforation. While, $80 \%$ of AC cases appeared as ill-defined multilocullar radiolucency and more than half of the cases $53.3 \%$ showed cortical perforation.

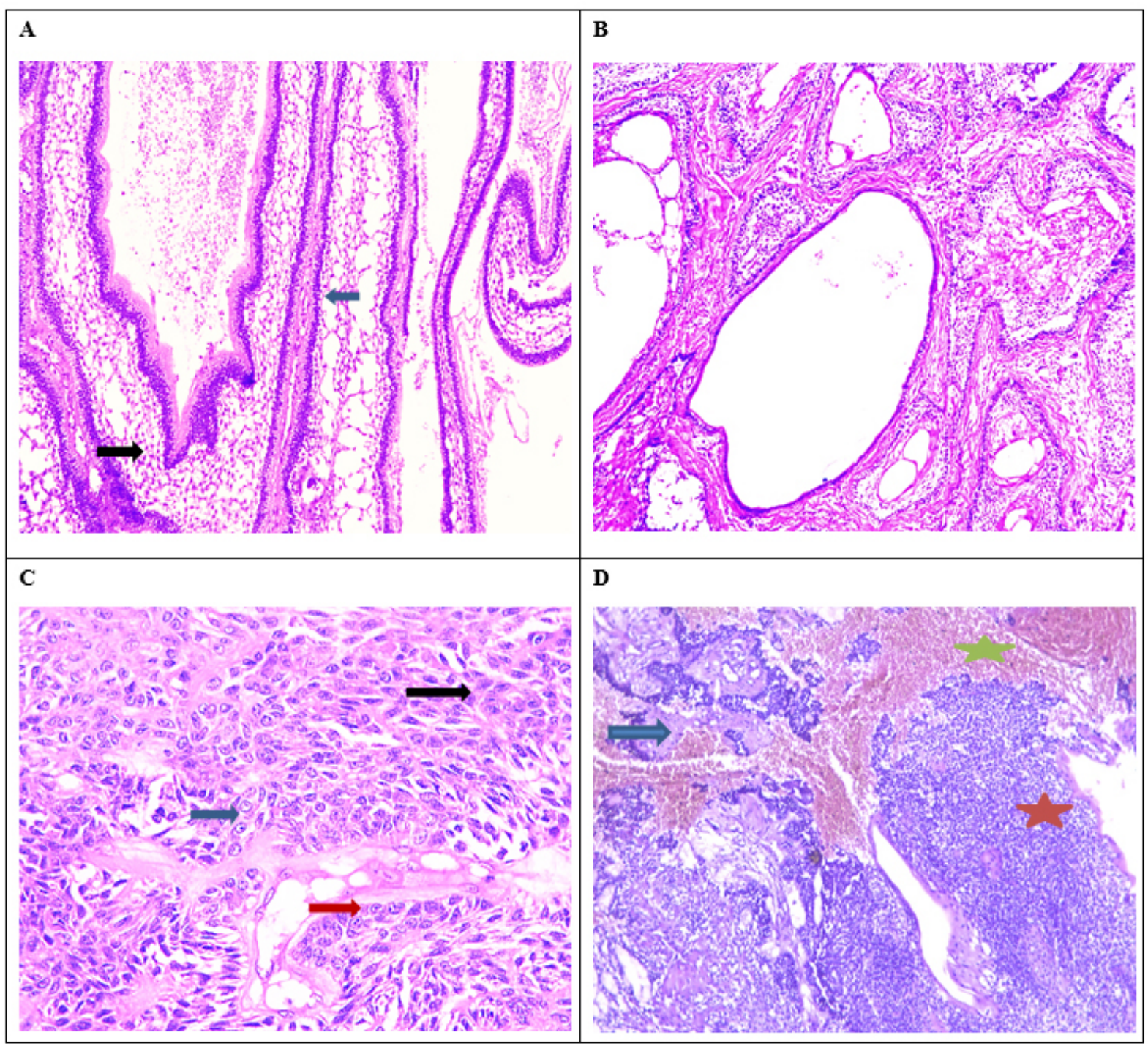

Figure 1. Photomicrographs showing (A) Conventional AB (Plexiform) showing: continuous anastomosing strands of peripheral epithelial cells (blue arrow) and central Stellate R.T like cells (black arrow) (H\&E $\times 100)$. (B) Follicular Ameloblastoma case: the epithelial cells are arranged in islands (follicles) (H\&E $\times 200)$. (C) Ameloblastic carcinoma case showing: the outer palisading cells lost their polarity and tend to be cuboidal in shape (red arrow), Cellular atypia (black arrow) and clear cells (blue arrow) $(\mathrm{H} \& \mathrm{E} \times 400)$. (D) Ameloblastic Carcinoma case showing: necrotic area (blue arrow), hemorrhage (green star) and undifferentiated area (red star) $(H \& E \times 100)$. 
Histologically, the studied cases were classified into19 Conventional $\mathrm{ABs}$, and $15 \mathrm{ACs}$. Out of 19 Conventional ABs; 4 different histological subtypes were presented as the following percentages: 8 Follicular (42.10\%), 6 Plexiform (31.50\%), 3 Desmoplastic (15.7\%) and 2 Acanthomatous $(10.5 \%)$ (see Figure 1A\&B). Three cases were recorded in patients' data sheets as recurrent cases. AC cases were formed of benign ameloblastomatous components which were invaded by malignant features such as: loss of normal cellular architecture, excessive hemorrhage, cellular atypia, mitotic activity, nuclear hyper chromatism, basilar hyperplasia, vas- cular invasion, clear cells and focal areas of necrosis (see Figure $1 \mathrm{~B} \& \mathrm{C})$.

SOX2 expression in $\mathrm{AB}$ was detected in $47.5 \%$ (9 out of 19 cases). High positive reactions represented $55.55 \%$ (5 cases) and $44.45 \%$ (4 cases) represented low positive reactions. Expression appeared in the nucleus of the outer basal epithelial cells of the neoplastic follicles and its presence ranged from weak to absent in the center. Moreover, infrequent stromal nuclear/cytoplasmic stromal reactions were also observed surrounding the neoplastic epithelial follicles (see Figure 2A).



Figure 2. photomicrographs showing: (A) SOX2 nuclear immune expression in a Follicular AB case in the outer palisading cells of a cystic follicle which decreased gradually inside and a slight stromal reaction surrounding the follicle (SOX2, PAP-DAB $\times 400$ ). (B) Ameloblastic carcinoma case showing: high positive SOX2 nuclear and cytoplasmic reaction in undifferentiated area (SOX2, PAP-DAB $\times 100$ ). (C) Desmoplastic AB case showing: high cytoplasmic GPC3 immune reaction in the epithelial cells and in the CT (GPC3, PAP-DAB $\times 100$ ). (D) Ameloblastic Carcinoma cases showing: diffuse GPC3 immune reaction (GPC3, PAP-DAB $\times 100)$. 
Furthermore, SOX2 expression in AC was found in $93.3 \%$ ( 14 cases out of 15 AC cases). $57.2 \%$ (8 cases) were scored high positive and $42.8 \%$ (6 cases) were scored low positive. It was a focal nuclear and cytoplasmic reaction near the tumor peripheries and in the areas that lost their normal cellular architecture. Stromal cytoplasmic reaction was observed as well (see Figure 2B).

GPC3 reaction in $\mathrm{AB}$ was observed in most of the cases $78.9 \%$ (15 cases). High positive scores were recorded in $47.5 \%$ (9 cases) and low positive scores were recorded in $31.5 \%$ (6 cases). It appeared in the cytoplasm of the outer palisading cells with variable expression inside the tumor follicles (see Figure 2C). Limited patchy nuclear expression was rarely observed.

Moreover, all the studied 15 AC cases exhibited diffuse GPC3 cytoplasmic/nuclear reactions in the tumor follicles and in the CT with weak staining in the center (see Figure 2D). High positive reactions were recorded in $53.3 \%$ (8 cases) and $46.7 \%$ (7 cases) were recorded as low positive.

Statistical analysis of SOX2 and GPC3 expressions among the studied cases revealed no significant differences between these markers and the clinical data [age, sex, site, radiographic appearance, and cortical perforation] $(p>.05)$.

Moreover, SOX2, and GPC3 were highly expressed in Desmoplastic $\mathrm{AB}$ in comparison with other $\mathrm{AB}$ subtypes without significant difference (see Table 1A). Furthermore, they were highly expressed in recurrent $\mathrm{AB}$ cases with statistically significant difference than non-recurrent ones (see Table 1B). In addition, AC had the highest scores in SOX2 and GPC3 when compared to AB with a significant difference (see Table 1C).

Table 1. SOX2 and GPC3 expressions in regard to (Conventional Ameloblastom subtypes), (Recurrence variable in Ameloblastom), and (Conventional Ameloblastoma and Ameloblastic carcinoma)

\begin{tabular}{|c|c|c|c|c|c|c|}
\hline & & & \multicolumn{2}{|c|}{ Sox2 Expression } & \multicolumn{2}{|c|}{ GPC3 Expression } \\
\hline & & & Mean Rank & $p$ & Mean Rank & $p$ \\
\hline \multirow{4}{*}{ A } & \multirow{4}{*}{ Con.AB Subtypes } & Follicular & 9.44 & \multirow{4}{*}{.07} & 9.33 & \multirow{4}{*}{.99} \\
\hline & & Acanthomatous & 13.00 & & 10.00 & \\
\hline & & Desmolastic & 15.25 & & 11.12 & \\
\hline & & Plexiform & 6.75 & & 9.92 & \\
\hline \multirow{2}{*}{ B } & \multirow{2}{*}{ Recurrence in $\mathrm{AB}$} & Yes & 27.00 & \multirow{2}{*}{$.003^{* *}$} & 24.50 & \multirow{2}{*}{$.02^{*}$} \\
\hline & & NO & 13.26 & & 13.90 & \\
\hline \multirow{2}{*}{$\mathrm{C}$} & Con. $\mathrm{AB}$ & & 17.79 & \multirow{2}{*}{$.001^{* *}$} & 19.57 & \multirow{2}{*}{$.02^{*}$} \\
\hline & $\mathrm{AC}$ & & 31.60 & & 28.17 & \\
\hline
\end{tabular}

Note. A-Test Used: Kruskal Wallis test; B, C -Mann Whitney test; ${ }^{*} p$ : significant at $<.05 ;{ }^{* *} p$ : significant at $<.01$

Table 2. Correlations of SOX 2 and GPC 3 among the studied casesl Ameloblastoma and Ameloblastic carcinoma)

\begin{tabular}{lccccc}
\hline & \multicolumn{2}{c}{ Con. AB } & & \multicolumn{2}{c}{ AC } \\
\cline { 2 - 5 } \cline { 4 - 6 } & $\boldsymbol{r}$ & $\boldsymbol{p}$ & $\boldsymbol{r}$ & $\boldsymbol{p}$ \\
\hline SOX2 exp. Vs. GPC3 exp. & 0.245 & .067 & & 0.473 & $.001^{* *}$ \\
\hline Note. Test Used: Spearman Correlation test; ${ }^{* *} p$ : significant at $<.01$ & & &
\end{tabular}

Investigation of the correlations among the studied groups revealed a high direct positive correlation with a significantly high difference between the expressions of SOX2 and GPC3 only in AC (see Table 2).

\section{Discussion}

Odontogenic tumors originate from the tissues of teeth forming apparatus due to the different degrees of inter-tissue interactions and the various growth patterns. ${ }^{[22]}$ Clinically and Published by Sciedu Press radio-graphically; both $\mathrm{AB}$ and $\mathrm{AC}$ are highly similar. However, $\mathrm{AC}$ can be expected if there are uncommon features of $\mathrm{AB}$ such as: rapid onset of swelling, pain, paresthesia and perforation of the cortical plate. ${ }^{[23]}$

In the present study, males were more affected than females in both $\mathrm{AB}$ and $\mathrm{AC}$. This was in accordance with previous studies. ${ }^{[23-27]}$ Smoking induces oral cancer risk development ${ }^{[28]}$ Cigarettes contains $\mathrm{N}$-nitrosamines and nicotine which lead to DNA mutations. This mutation encourages tu- 
mor initiation and promotion. Moreover, about sixty known carcinogens have been identified in cigarette smoke that are involved in cancer. ${ }^{[29]}$ Smoking is a very common habit of males especially in our society. This supports these study results. To the contrary, equal gender distribution in $\mathrm{AB}$ was recorded previously. ${ }^{[30]}$ This reveals gender varieties in different populations.

Regarding the age distribution, mean age of the current $A B$ cases was 35.28 which is in line with the findings of Hendra et al., 2020. ${ }^{[24]}$ Moreover, the mean age of the currently studied AC cases was 45.53. That is similar to the findings of Pandey et al., 2018 and Noureldin and Ragab. 2019. ${ }^{[23,31]}$ Aging may predispose to cancer due to the disturbances in immune and endocrine systems. It is also associated with variations in molecular, cellular and systemic levels that influence carcinogenesis and subsequent cancer growth. Moreover, prolonged exposure to environmental carcinogens along the life span increases the liability for tumors. ${ }^{[32]}$ This may explain why $\mathrm{AC}$ patients usually have a higher age range than benign $\mathrm{AB}$ as was presented in this research.

Previous reports, stated that the posterior mandible was the most common site similar to this study findings. ${ }^{[30,33,34]}$ The posterior mandible is the most susceptible site because of its rich blood supply ${ }^{[35]}$ which is important for preserving tumor growth as it supplies tumors with their needs of oxygen and nutrients. Moreover, it provides a suitable path for tumor metastasis. ${ }^{[36]}$

Regarding the radiographic appearance, most of the currently studied AB cases appeared as well-defined multilocular radiolucency without cortical perforation. In addition, all AC cases had a more aggressive pattern with ill-defined margins and a destructed cortical plate. These findings were similar to the radiographic picture identified by the WHO in 2017. ${ }^{[37]}$ These findings reflect the variations in the biological behavior of these lesions (benign and malignant) indicating the importance of radiographing in predicting the correct diagnosis.

This study has found histologically that the follicular pattern was mostly observed followed by the Plexiform pattern. However, the Acanthomatous one was rare. Similar observations were reported previously. ${ }^{[2,38]}$ To the contrary, the Plexiform pattern was the commonest type as was reported by Martínez et al., 2017. [27]

In agreement with previous researches, ${ }^{[23,29]}$ benign features of $\mathrm{AB}$ were commonly seen in the current studied $\mathrm{AC}$ cases. Moreover, malignant diagnostic components such as: loss of normal cellular architecture, excessive hemorrhage, cellular atypia, mitotic activity, nuclear hyperchromatism, vascular invasion, clear cells and focal areas of necrosis were also reported in different previous studies. ${ }^{[27,33,40,41]}$

SOX2 protein has significant roles in regulating stem cell characters. ${ }^{[42]}$ Furthermore, it has been linked to the process of tumorigenesis, destructive clinical course and poor prognosis. ${ }^{[43]}$ SOX2 wasn't found in most of the currently studied AB cases, the same as the findings of Lei et al., 2014 and Silva et al., 2020. ${ }^{[44,45]}$ On the other hand, a recent study by Pagella et al.,2020 ${ }^{[46]}$ has documented that SOX2 was highly expressed by AB. Moreover, Banerjee et al., 2016 [47] stated a total absence of SOX2 in all their studied AB cases. These conflicting results could be explained on the basis of a recent study on the genetic alterations of $\mathrm{AB}^{[48]}$ which found multiple gene mutations only in European patients except the Turkish ones. These finding suggested differences in genetic backgrounds defining different mutational spectra.

Moreover, Chang et al., 2019 ${ }^{[49]}$ found that SOX2 expression was significantly higher in ABs with mutated BRAF than that with non-mutated ones. They suggested that mutated BRAF may encourage the expansion of SOX2 positive cells. Hence, further studies are needed to clearly approve these results.

SOX2 expression in AB was mainly nuclear in agreement with previous studies ${ }^{[20,44]}$ In AC, it was always nuclear and cytoplasmic as was reported in a recent study by Silva et al., 2020. ${ }^{[45]}$ Van Schaijik et al.,2018 ${ }^{[50]}$ mentioned that SOX2 showed both nuclear and cytoplasmic expressions in a range of cancers, suggesting a function dependent on its subcellular kinetics. This might be related to differentiating potentials. Therefore, the cytoplasmic expression of SOX 2 could be an indicator for more tumor aggressiveness.

Overexpression of SOX2 was correlated to the recurrence and the metastasis in head and neck SCC as well as to the presence of CSCs. ${ }^{[9,51]}$ In the present study, SOX2 was strongly observed in all the recurrent $\mathrm{AB}$ specimens with a significant difference when compared with non-recurrent ones. This might contribute to the formation of recurrent and more aggressive ABs and strongly suggests the presence of CSCs. This was in agreement with Sanjai et al., 2018 ${ }^{[52]}$ who suggested that SOX2 overexpression in recurrent AB can be used to follow-up the patients.

Distinguishing between $\mathrm{AC}$ and aggressive $\mathrm{AB}$ is challenging. Because $\mathrm{AC}$ has the benign features of $\mathrm{AB}$ in addition to the malignant parts. In this study, almost all AC cases were SOX2 positive in agreement with previous studies. ${ }^{[14,52]}$ This strongly suggests the presence of more CSCs in AC which promotes the aggressiveness and progression of it. Moreover, SOX2 protein wasn't found in most of the studied AB cases as they behave less aggressively than AC. This is similar to the findings of Silva et al., 2020. ${ }^{[45]}$ 
According to the current study results, SOX2 was higher in $\mathrm{AC}$ than was in $\mathrm{AB}$ with a significant difference in line with the findings of previous studies. ${ }^{[20,44,52]}$ Therefore, SOX2 expression may be related to the degree of tumorigenesis in OTs and could be a beneficial marker in detecting areas undergoing malignant changes in $\mathrm{AB}$.

Glypicans are heparin sulfate proteoglycans (HSPG), it can act as co-receptor to regulate cell proliferation, division, and motility. ${ }^{[53]}$ Any deletion or mutation of GPC3 can disturb the biological balance between proliferation and apoptosis that ends to tumorigenesis. ${ }^{[54]}$

In specific considerations, only two studies ${ }^{[21,55]}$ in English literature have investigated GPC3 in OTs. They found GPC3 immune staining in the cytoplasm/membranes of the tumor cells the same as this study. This expression pattern depends on the nature of the glypicans members as they are attached to the plasma membrane glycosyl- phosphatidylinositol linkage. They are also present in the cytoplasm and can be secreted to the ECM through the action of notum. ${ }^{[56]}$

In this study, GPC3 was highly expressed in all the recurrent $\mathrm{AB}$ specimens with a significant difference than nonrecurrent ones. This suggests that GPC3 overexpression provides an idea about the aggressiveness degree of such a tumor. It may as well act as a prognostic factor for recurrence in OTs. Studies on $\mathrm{HCC}^{[57-59]}$ correlated high GPC3 expression to a high recurrence rate. However, similar studies on OTs aren't applied till now. Hence, future studies on a large number of samples are required to evaluate the actual role of GPC3 and its relation to recurrence in ABs.

This is the first study in English literature investigating GPC3 expression in AC. It exhibited higher expression in $\mathrm{AC}$ than was in $\mathrm{AB}$ with a significant difference. A recent study by Azadeh Tadbir et al., 2019 ${ }^{[54]}$ on salivary gland tumors has documented higher levels of GPC 3 in benign tumors than normal tissues and observed overexpression of GPC 3 in malignant tumors than in benign ones. Moreover, abundant expression has been documented in different malignant types of tumors, ${ }^{[18,60,61]}$ which indicates its role in the carcinogenesis and the more aggressiveness behavior. However, additional future studies on OTs are needed in this context to stand on its actual role in these tumors.

In addition, GPC 3 expression was observed in fibroblasts nearest to the tumor cells in both AB and AC. GPC3 acts as a co-receptor for basic growth factors such as fibroblast growth factor2 through its HSPG chain. ${ }^{[62]}$ This suggests that GPC3 might involve in the storage of heparin-depending growth factors, which are released by the heparanase at the beginning of infiltration, invasion and induce mitogenic stimulation of cancer cells as was mentioned by Gómez-Herrera et al., 2018. ${ }^{[56]}$

The current work has evaluated the expression of SOX2 and GPC3 markers according to the histological patterns of Conventional $\mathrm{AB}$. The current study found that the Desmoplastic subtype had the highest levels of SOX2 and GPC 3 than the other subtypes without a significant difference. These findings could be due to the more aggressive nature of the Desmoplastic type as was mentioned by Ranjan et al., 2019. ${ }^{[63]}$ In addition, these results also suggest the presence of more numbers of stem cells than other subtypes. However, the published data about Conventional $\mathrm{AB}$ subtypes regarding the proliferative and invasiveness indexes are still very controversial.

Finally, the current work has explored the correlations between these markers and the clinical data in the studied groups. No significant differences were detected with any of them. This is attributed to the small sample size of this research. Hence, it's better to investigate their correlations with the clinical data on a larger number of samples. Moreover, direct positive correlation between their expressions was detected in AC. This correlation might allow using them as a panel to diagnose $\mathrm{AC}$ rather than the aggressive $\mathrm{AB}$.

\section{CONFlicts OF InTEREST Disclosure}

The authors declare no conflict of interest.

\section{REFERENCES}

[1] Bilodeau EA, Collins BM. Odontogenic Cysts and Neoplasms. Surgical pathology clinics. 2017; 10(1): 177-222. PMid: 28153133. https://doi.org/10.1016/j.path.2016.10.006

[2] Effiom OA, Ogundana OM, Akinshipo AO, et al. Ameloblastoma: current etiopathological concepts and management. Oral Diseases. 2018; 24(3): 307-316. PMid: 28142213. https ://doi.org/10.1 111/odi. 12646

[3] Braimah R, Uguru C, Ndukwe K. Ameloblastic carcinoma of the

Published by Sciedu Press jaws: Review of the literature. Journal of Dental and Allied Sciences. 2017; 6(2): 70. https://doi.org/10.4103/jdas.jdas_4_17

[4] Moro A, Foresta E, Gasparini G, et al. Ameloblastic carcinoma of the maxilla: A case report and an updated review of the literature. Oncology Letters. 2016; 12(6): 4339-4350. PMid: 28105148. https://doi.org/10.3892/ol.2016.5272

[5] Nagi R, Sahu S, Rakesh N. Molecular and genetic aspects in the etiopathogenesis of ameloblastoma: An update. Journal of Oral and Maxillofacial Pathology. 2016; 20(3): 497. PMid: 27721617. 
https://doi.org/10.4103/0973-029X.190954

[6] Ayob AZ, Ramasamy TS. Cancer stem cells as key drivers of tumour progression. Journal of Biomedical Science. 2018; 25(1): 1-18. PMid: 29506506. https://doi.org/10.1186/s12929-018-0426-4

[7] Yang L, Shi P, Zhao G, et al. Targeting cancer stem cell pathways for cancer therapy. Signal Transduction and Targeted Therapy. 2020; 5(1): 1-35. PMid: 32296030. https ://doi.org/10.1038/s413 92-020-0110-5

[8] Song WS, Yang YP, Huang CS, et al. Sox2, a stemness gene, regulates tumor-initiating and drug-resistant properties in CD133positive glioblastoma stem cells. Journal of the Chinese Medical Association. 2016; 79(10): 538-545. PMid: 27530866. https: //doi.org/10.1016/j.jcma.2016.03.010

[9] Ren ZH, Zhang CP, Ji T. Expression of SOX2 in oral squamous cell carcinoma and the association with lymph node metastasis ( $\mathrm{Re}$ view). Oncology Letters. 2016; 11(3): 1973-1979. PMid: 26998109. https://doi.org/10.3892/ol.2016.4207

[10] Zhang S, Xiong X, Sun Y. Functional characterization of SOX2 as an anticancer target. Signal Transduction and Targeted Therapy. 2020; 5(1): 1-17. PMid: 32728033. https ://doi.org/10.1038/s413 92-020-00242-3

[11] Zhang M, Zhang X, Luo J, et al. Investigate the Odontogenic Differentiation and Dentin-Pulp Tissue Regeneration Potential of Neural Crest Cells. Frontiers in Bioengineering and Biotechnology. 2020; 8 : 475. PMid: 32582651. https ://doi.org/10.3389/fbioe. 2020 .00475

[12] Chaudhary S, Islam Z, Mishra V, et al. Sox2: A Regulatory Factor in Tumorigenesis and Metastasis. Current Protein \& Peptide Science. 2019; 20(6): 495-504. PMid: 30907312. https ://doi.org/10.2 $174 / 1389203720666190325102255$

[13] Novak D, Hüser L, Elton JJ, et al. SOX2 in development and cancer biology. Seminars in Cancer Biology. 2020; 67: 74-82. PMid: 31412296. https://doi.org/10.1016/j.semcancer. 2019.0 8.007

[14] Sobhy AM, Fouad HMA, Riad SM, et al. EVALUATION OF SOX2 AS A POTENTIAL STEM CELL MARKER IN BENIGN AND MALIGNANT ODONTOGENIC TUMORS. Alexandria Dental Journal. 2019; 44(3): 99-105. https://doi.org/10.21608/adjalexu 2019.63566

[15] Meng P, Zhang YF, Zhang W, et al. Identification of the atypical cadherin FAT1 as a novel glypican-3 interacting protein in liver cancer cells. Scientific Reports. 2021; 11(1): 40. PMid: 33420124. https://doi.org/10.1038/s41598-020-79524-3

[16] Kolluri A, Ho M. The Role of Glypican-3 in Regulating Wnt, YAP, and Hedgehog in Liver Cancer. Frontiers in Oncology. 2019; 9. PMid: 31428581. https://doi.org/10.3389/fonc. 2019.00708

[17] Montalbano M, Rastellini C, McGuire JT, et al. Role of Glypican-3 in the growth, migration and invasion of primary hepatocytes isolated from patients with hepatocellular carcinoma. Cellular Oncology. 2018; 41(2): 169-184. PMid: 29204978 https ://doi .org/10.1 007/s13402-017-0364-2

[18] Moek KL, Fehrmann RSN, van der Vegt B, et al. Glypican 3 Overexpression across a Broad Spectrum of Tumor Types Discovered with Functional Genomic mRNA Profiling of a Large Cancer Database. American Journal of Pathology. 2018; 188(9): 1973-1981. PMid: 29935166. https://doi.org/10.1016/j.ajpath.2018.05.0 14

[19] Soluk-Tekkeşin M, Wright JM. The world health organization classification of odontogenic lesions: A summary of the changes of the 2017 (4th) edition. Turk Patoloji Dergisi. 2018; 34(1): 1-18 https://doi.org/10.5146/tjpath.2017.0141028984343
[20] Khan W, Augustine D, Rao R, et al. Stem Cell Markers SOX2 and OCT-4 Enable to Resolve the Diagnostic Dilemma between Ameloblastic Carcinoma and Aggressive Solid Multicystic Ameloblastoma. Advanced Biomedical Research. 2018; 7(1): 149. PMid: 30596059. https://doi.org/10.4103/abr.abr_135_ 18

[21] Mendes RB, Dias RB, Figueiredo AL, et al. Glypican-3 distinguishes aggressive from non-aggressive odontogenic tumors: a preliminary study. Journal of Oral Pathology and Medicine. 2017; 46(4): 297-300. PMid: 27647326. https ://doi.org/10.1111/jop. 12501

[22] Población U, Rayssa B, Cavalcante M, et al. Epithelial Odontogenic Tumors: Analysis of 156 Cases in a Brazilian Population Tumores Odontogénicos Epiteliales: Análisis de 156 Casos En. 2016; 10. https://doi.org/10.4067/S0718-381X2016000100018

[23] Pandey S, Bhutia O, Roychoudhury A, et al. Literature review of 86 cases of mandibular ameloblastic carcinoma. National Journal of Maxillofacial Surgery. 2018; 9(1): 2. PMid: 29937652. https://doi.org/10.4103/njms.NJMS_33_16

[24] Hendra FN, Van Cann EM, Helder MN, et al. Global incidence and profile of ameloblastoma: A systematic review and metaanalysis. Oral Diseases. 2020; 26(1): 12-21. PMid: 30614154. https://doi.org/10.1111/odi.13031

[25] Cadavid AMH, Araujo JP, Coutinho-Camillo CM, et al. Ameloblastomas: current aspects of the new WHO classification in an analysis of 136 cases. Surgical and Experimental Pathology. 2019; 2(1): 17. https://doi.org/10.1186/s42047-019-0041-z

[26] Deng L, Wang R, Yang M, et al. Ameloblastic carcinoma: Clinicopathological analysis of 18 cases and a systematic review. Head and Neck. 2019; 41(12): 4191-4198. PMid: 31444935. https: //doi.org/10.1002/hed. 25926

[27] Martínez-Martínez M, Mosqueda-Taylor A, Carlos-Bregni R, et al. Comparative histological and immunohistochemical study of ameloblastomas and ameloblastic carcinomas. Medicina Oral, Patologia Oral y Cirugia Bucal. 2017; 22(3): e324-e332. PMid: 28390135 https://doi.org/10.4317/medoral.21901

[28] Prasetyaningtyas N, Jatiatmaja NA, Radithia D, et al. The Response of the Tongue Epithelial on Cigarette Smoke Exposure as a Risk Factor for Oral Cancer Development. European Journal of Dentistry. 2020; 15(02): 320-324. PMid: 33285573. https://doi.org/10 $.1055 / \mathrm{s}-0040-1721312$

[29] Kwong A. Is Smoking a Risk Factor of Breast Cancer? Novel Approaches in Cancer Study. 2019; 2(3). https : //doi .org/10.310 31/NACS. 2019.02.000540

[30] Intapa C. Analysis of prevalence and clinical features of ameloblastoma and its histopathological subtypes in Southeast Myanmar and lower Northern Thailand populations: A 13-year retrospective study. Journal of Clinical and Diagnostic Research. 2017; 11(1): ZC102ZC106. https://doi.org/10.7860/JCDR/2016/23629.9295

[31] Noureldin M, Ragab H. Latest update of odontogenic tumors in Alexandria University, Egypt: A 5-year retrospective study using WHO 2017 classification. Egyptian Dental Journal. 2019; 65(3): 2115-2124. https ://doi .org/10.21608/edj . 2019.72229

[32] Rozhok A, De Gregori J. A generalized theory of age-dependent carcinogenesis. eLife. 2019; 8: 1-23. PMid: 31034356. https : //doi.org/10.7554/eLife. 39950

[33] Mahmoud SAM, Amer HW, Mohamed SI. Primary ameloblastic carcinoma: Literature review with case series. Polish Journal of Pathology. 2018; 69(3): 243-253. PMid: 30509051. https: //doi.org/10.5114/pjp.2018.79544

[34] Nalabolu GRK, Mohiddin A, Hiremath SKS, et al. Epidemiological study of odontogenic tumours: An institutional experience. Journal of 
Infection and Public Health. 2017; 10(3): 324-330. PMid: 27425795. https://doi.org/10.1016/j.jiph.2016.05.014

[35] Hasheminasab M, Karimi A, Parizi MK, et al. Metastasis of a prostate adenocarcinoma to mandible: A case report and review of literature. Clinical Case Reports. 2020; 8(10): 2063-2066. PMid: 33088553. https://doi.org/10.1002/ccr3.3065

[36] Teleanu RI, Chircov C, Grumezescu AM, et al. Tumor Angiogenesis and Anti-Angiogenic Strategies for Cancer Treatment. Journal of Clinical Medicine. 2019; 9(1): 84. PMid: 31905724. https: //doi.org/10.3390/jcm9010084

[37] El-Naggar AK, Chan JKC, Takata T, et al. The fourth edition of the head and neck World Health Organization blue book: editors' perspectives. Human Pathology. 2017; 66: 10-12. PMid: 28583885. https://doi.org/10.1016/j.humpath.2017.05.014

[38] Patsa S, Jadav R, Halder G, et al. Demographic and histopathological variation of ameloblastoma: A hospital-based study. Journal of Oral and Maxillofacial Pathology. 2016; 20(2): 230. PMid: 27601814. https://doi.org/10.4103/0973-029X.185937

[39] Smitha T, Priya NS, Hema KN, et al. Ameloblastic carcinoma: A rare case with diagnostic dilemma Case Report. Published online 2019. PMid: 30967729. https://doi.org/10.4103/jomfp. JO MFP_318_18

[40] Flucke U. Malignant Neoplasms of the Gnathic Bones. In: Head and Neck Pathology: A Volume in the Series: Foundations in Diagnostic Pathology. Elsevier; 2019. 417-432 p. https://doi.org/10.101 6/B978-0-323-47916-5.00016-9

[41] Yiannis C, Mascolo M, Mignogna MD, et al. Expression profile of stemness markers cd138, nestin and alpha-sma in ameloblastic tumours. International Journal of Environmental Research and Public Health. 2021; 18(8): 18. PMid: 33917771. https://doi .org/10 .3390/ijerph18083899

[42] Hagey DW, Klum S, Kurtsdotter I, et al. SOX2 regulates common and specific stem cell features in the CNS and endoderm derived organs. PLoS genetics. 2018; 14(2): e1007224. PMid: 29432416. https://doi.org/10.1371/journal.pgen.1007224

[43] Zhang S, Xiong X, Sun Y. Functional characterization of SOX2 as an anticancer target. Signal Transduction and Targeted Therapy. 2020; 5(1): 135. PMid: 32728033. https://doi.org/10.1038/s413 92-020-00242-3

[44] Lei Y, Jaradat JM, Owosho A, et al. Evaluation of SOX2 as a potential marker for ameloblastic carcinoma. Oral surgery, oral medicine, oral pathology and oral radiology. 2014; 117(5): 608-616.e1. PMid: 24603057. https://doi.org/10.1016/j.0000.2014.01.017

[45] Silva BS de F, Silva LR, de Lima KL, et al. Sox2 and bcl-2 expressions in odontogenic keratocyst and ameloblastoma. Medicina Oral Patologia Oral y Cirugia Bucal. 2020; 25(2): e283-e290. PMid: 31967981. https://doi.org/10.4317/medoral.23348

[46] Pagella P, Catón J, Meisel CT, et al. Ameloblastomas Exhibit Stem Cell Potential, Possess Neurotrophic Properties, and Establish Connections with Trigeminal Neurons. Cells. 2020; 9(3): 644. PMid: 32155948. https://doi.org/10.3390/cells9030644

[47] Banerjee A, Kamath V, Sundaram L, et al. OCT4 and SOX2 are reliable markers in detecting stem cells in odontogenic lesions. Journal of Orofacial Sciences. 2016; 8(1): 16. https ://doi .org/10.410 3/0975-8844.181920

[48] Gültekin SE, Aziz R, Heydt C, et al. The landscape of genetic alterations in ameloblastomas relates to clinical features. Virchows Archiv. 2018; 472(5): 807-814. PMid: 29388014. https://doi .or $\mathrm{g} / 10.1007 / \mathrm{s} 00428-018-2305-5$

[49] Chang DJYF, Tseng DC-H, Lu DPH, et al. Increased sox2-positive cells in braf(v600e) mutated ameloblastomas. Oral Surgery, Oral
Medicine, Oral Pathology and Oral Radiology. 2019; 128(1): e49e50. https://doi.org/10.1016/j.0000.2019.02.105

[50] Van Schaijik B, Davis PF, Wickremesekera AC, et al. Subcellular localisation of the stem cell markers OCT4, SOX2, NANOG, KLF4 and c-MYC in cancer: A review. Journal of Clinical Pathology. 2018; 71(1): 88-91. PMid: 29180509. https://doi.org/10.1136/jc linpath-2017-204815

[51] Vijayakumar G, Narwal A, Kamboj M, et al. Association of SOX2, OCT4 and WNT5A Expression in Oral Epithelial Dysplasia and Oral Squamous Cell Carcinoma: An Immunohistochemical Study. Head and Neck Pathology. Published online January 4, 2020; 1-9. PMid: 31902091. https://doi.org/10.1007/s12105-019-01114-1

[52] Sanjai K, Sangappa SB, Shivalingaiah D, et al. Expression of SOX2 and EGFR in Ameloblastoma, Odontoameloblastoma and Ameloblastic Carcinoma. Journal of Clinical and Diagnostic Research. 2018; 12(7): 8-12. https://doi.org/10.7860/JCDR/2 018/34269.11800

[53] Li N, Spetz MR, Ho M. The Role of Glypicans in Cancer Progression and Therapy. Journal of Histochemistry and Cytochemistry. 2020; 68(12): 841-862. PMid: 32623934. https://doi.org/10.1369/ 0022155420933709

[54] Andisheh-Tadbir A, Ashraf MJ, Gudarzi A, et al. Evaluation of Glypican-3 expression in benign and malignant salivary gland tumors. Journal of Oral Biology and Craniofacial Research. 2019; 9(1): 63-66. PMid: 30294537. https://doi.org/10.1016/j.jobcr. 2018.09.002

[55] Azadeh AT, Elnaz K, Razieh Z. Glypican-3 Expression in Dentigerous Cyst, Odontogenic Keratocyst andRadicular Cyst. 2018; 14(3): 305-312.

[56] Gómez-Herrera Z, Molina-Frechero N, Damián-Matsumura P, et al. Proteoglycans as potential biomarkers in odontogenic tumors. Journal of Oral and Maxillofacial Pathology. 2018; 22(1): 98-102. https://doi.org/10.4103/jomfp. JOMFP_151_17

[57] Miura M, Fujinami N, Shimizu Y, et al. Usefulness of plasma fulllength glypican-3 as a predictive marker of hepatocellular carcinoma recurrence after radial surgery. Oncology Letters. Published online February 5, 2020. https://doi.org/10.3892/o1.2020.11371

[58] Guo M, Zhang H, Zheng J, et al. Glypican-3: A new target for diagnosis and treatment of hepatocellular carcinoma. Journal of Cancer. 2020; 11(8): 2008-2021. PMid: 32127929. https ://doi.org/10 $.7150 /$ jca. 39972

[59] Guo Z, Wang J, Li L, et al. Value of miR-1271 and glypican-3 in evaluating the prognosis of patients with hepatocellular carcinoma after transcatheter arterial chemoembolization. World Journal of Clinical Cases. 2020; 8(16): 3493-3502. PMid: 32913856. https://doi.org/10.12998/wjcc.v8.i16.3493

[60] Andisheh-Tadbir A, Goharian AS, Ranjbar MA. Glypican-3 Expression in Patients with Oral Squamous Cell Carcinoma. Journal of dentistry (Shiraz, Iran). 2020; 21(2): 141-146. https ://doi .org/ 10.30476/DENT JODS . 2019.84541.108932582830

[61] Wu Q, Pi L, Le Trinh T, et al. A Novel Vaccine Targeting Glypican-3 as a Treatment for Hepatocellular Carcinoma. Molecular Therapy. 2017; 25(10): 2299-2308. PMid: 28865999. https : //doi .org/10 $.1016 / j$. ymthe .2017 .08 .005

[62] Montalbano M, Georgiadis J, Masterson AL, et al. Biology and function of glypican-3 as a candidate for early cancerous transformation of hepatocytes in hepatocellular carcinoma (Review). Oncology Reports. 2017; 37(3): 1291-1300. PMid: 28098909. https://doi.org/10.3892/or.2017.5387

[63] Ranjan V, Chakrabarty S, Arora P, et al. Desmoplastic Ameloblastoma of the Mandible: A Rare Case Report. Journal of Indian Academy of Oral Medicine and Radiology. 2019; 31(1): 36-39. https://doi.org/10.4103/jiaomr.jiaomr 